\title{
Comentario sobre la música y el desarrollo integral del niño
}

\section{Coments about the music and integral development of the child}

\section{Sra. Editora:}

Hemos leído atentamente el artículo "La música y el desarrollo integral del niño" publicado en el último número de la Revista Enfermería Herediana (1). Nos pareció interesante lo mencionado, pero en nuestra opinión en el estudio se debió detallar o considerar 3 aspectos relevantes.

Primero, la intensidad del volumen con que se hará escuchar la música al niño, evitar volumen alto que afecte la capacidad auditiva aguda de los niños debido a que volúmenes que sobrepasen los 45 decibeles puede ocasionar pérdida aguda de la audición (2).

Segundo, el origen o la fuente de la música, la que puede provenir del canto, arrullo de la madre o cuidador en el contacto constante a través del cual brinda cuidado al niño (3).
Tercero, considerar los principios de la estimulación a los niños como el que sea adecuada a la edad, a las necesidades y que no interfiera con su desarrollo.

\section{Rosa Vaiz Bonifaz ${ }^{1, a}$, Nidia Bolaños Sotomayor ${ }^{1}$. \\ REFERENCIAS BIBLIOGRÁFICAS}

1. Romero E. La música y el desarrollo integral del niño. Rev enferm Herediana. 2017;10(1):9-13. DOI: https://doi.org/10.20453/renh.v10i1.3125

2. Magán-Hervás A, Gértrudix-Barrio F. Influencia de las actividades audio-musicales en la adquisición de la lectoescritura en niños y niñas de cinco años. EDUCARE. 2017; 21(1): 1-22.

3. Pineda E, Pérez Y. Musicoterapia aplicada a niños con síndrome de Down. Rev Cubana Pediatr. 2011; 83(2): $142-148$.

Evelyn Melina Romero Abanto autora del artículo "La música y el desarrollo integral del niño" publicado en la Revista Enfermería Herediana 2017;10(1) agradece el aporte de las autoras debido que complementa el artículo publicado. 